\title{
GEOMATICS IN THE MANAGEMENT OF BUILT HERITAGE THROUGH BIM SYSTEMS. THE TRAINING OF NEW EXPERIENCED PROFESSIONAL FIGURES.
}

\author{
A.Adami ${ }^{1 *}$, L. Fregonese ${ }^{1}$ \\ ${ }^{1}$ Dept. of Architecture, Built Environment and Construction engineering (dABC), \\ Heritage Survey Technology group (HeSuTech), MantovaLab, \\ Politecnico di Milano, Polo territoriale di Mantova, via Angelo Scarsellini, 15, 46100 Mantova, Italy \\ (andrea.adami, luigi.fregonese)@polimi.it
}

Commission V, WG V/1

KEYWORDS: Training curriculum, Geomatics, HBIM

\begin{abstract}
:
Geomatics is trying to redefine its role in the Italian higher-level educational system according to the new technological developments. The recent thematic thread of Building Information Modelling (BIM) systems contributes to the new role of Geomatics inside universities and, more generally, in the training process. BIM systems propose new ways of managing the construction process throughout building life cycle, from design to construction and management. They allow managing large flows of information, organized and shared among the different operators in the construction chain, through databases linked to threedimensional objects. The BIM approach is based on two principles: interoperability and digitization.

BIM was born as an application dedicated to new buildings, to promote the optimization of the entire life cycle of the building, from design to management. Many countries have been active in this sector for years, while others are now joining the digitization approach. In this complex scenario, the proposal to adopt the BIM process not only for the management of new constructions but also for the intervention on the existing one, is relevant in a country, like Italy, with a very rich history and a high presence of built historical heritage. Maurice Murphy coined the term HBIM (Historic Building Information Modelling), referring to BIM systems applied to historical buildings that need intervention and subsequent management.

Geomatics plays a crucial role in HBIM as it is the primary tool for the digitization of built heritage and to obtain a model of the existing, an "as-built" model. In order to achieve this result, laser scanner and photogrammetry are the main tools, and they are involved in the so-called Scan2Bim process. The other important role is connected with the modeling stage to arrive at a threedimensional representation suitable for common BIM authoring software while maintaining the rigor and accuracy that characterize the geomatic approach.

The fundamental role of Geomatics in this context requires the training of personnel specialized in surveying and managing the acquired data through HBIM systems. There are new training courses and masters in the field of BIM systems, hosted by Politecnico di Milano at the Mantua Campus, aimed at training new figures with a specific curriculum, including Geomatics.

The elements that characterize the training course are the knowledge of the principles and methods of data and the evaluation of achievable accuracy and admissible errors. It is also important to address issues that are still not completely solved in HBIM community, such as the type of modeling the best levels of detail of geometric and information content and the most practical aspects of commercial BIM authoring software.

The article describes the experience carried out by Politecnico di Milano and tries to define, afterward, the training curriculum for HBIM experts, in which Geomatics plays an essential role, not only in the data acquisition phase but also in geometric and informative modeling.
\end{abstract}

\section{INTRODUCTION}

\subsection{BIM adoption and training.}

Building Information Modelling (BIM) is one of the most interesting and topical issues both in the professional and research fields.

The adoption of new systems for the management of the construction supply chain, in all its stages, represents a resource in the professional field for the many advantages it brings, like improved efficiency, reduced waste, and better project management. Digitalization is very relevant for private sector companies as they have financial interests in the passage to the latest digital technologies. The overall business impact of BIM is apparent in industry figures. The estimated value for the
European BIM market was 1.8 billion EUR in 2016, and it is expected to grow up to 2.1 billion EUR by 2023 (European Construction Sector Observatory, 2019).

However, BIM also represents a significant step forward for the public sector; it allows to reach relevant social outcomes, especially related to the topics of urbanization, population growth and energy efficiency upgrading. We should also consider the advantages, for public sector, in the management of public buildings with more efficient public spending and a more sustainable use of shared spaces.

We should also consider all the improvements connected with better building quality and efficiency, management of built environment, sustainability, and budgeting.

The growing interest in BIM, justified by all these advantages,

\footnotetext{
* Corresponding author
} 
is also proven by its increasing popularity and adoption, supported by the regulations of individual countries (public) and by the industry (private).

We can see a confirmation of this great interest in the establishment of EU BIM Task Group in 2016 (http://www.eubim.eu/), which aims to develop a world-class digital construction sector. The group published a handbook (EU BIM Task group, 2018), intended to encourage a wider introduction of BIM in response to the growing challenges faced by governments across Europe and public clients to stimulate economic growth and competitiveness while delivering value for public money. It also demonstrates the importance of coordinated public sector action across both European and national levels to drive towards this vision.

In the same direction of public involvement for the support of BIM, we can count the numerous standardization initiatives proposed by many European or institutions. From the "International Organization for Standardization" (committee ISO/TC 59/SC), and the "European Committee for Standardization (committee CEN/TC 442, to the regional ones (in Italy, they are represented by UNI).

We should also mention the efforts of BuildingSmart (https://www.buildingsmart.org) in the definition of IFC (Industry Foundation Classes) to foster the exchange and sharing of data among different BIM software.

In spite of the many efforts to spread this digitalization approach, we observe that the level of BIM adoption in different countries is very different. In a schematization, (Panteli et al. 2020) state that the countries that are more advanced in the national legislation adoption process are those of Northern Europe and in particular Finland, Sweden, Netherlands, Norway, and the United Kingdom. An intermediate situation, instead, regards a group of countries that are moving towards the adoption of BIM systems, by the definition of a roadmap and standards in digitization procedures. Among them, we count France, Italy, Germany, Spain, Austria, and Denmark. Finally, the last group, with the Czech Republic, Lithuania, Cyprus, and Greece, is still at low levels, although growing.

A large number of educational activities support the increased adoption of BIM. Many universities and research centers offer training courses in BIM. These are generally postgraduate masters, more or less specialized in a specific sector of the complex BIM environment. There are also professionalizing courses, even more specific, which are often held by private institutions, which are part of the construction sector. On the contrary, it seems that there are no degrees specifically dedicated to BIM, and the single courses are mainly in engineering faculties and, only in a small part, in architecture.

\subsection{Italian adoption of BIM.}

The proposal of a specific curriculum related to BIM systems applied to the built environment deals with the local situation. For this reason, it is appropriate to better study the Italian case, in particular, analyzing the legislation, the adoption of the BIM, and even the construction sector.

From a legislative point of view, the fundamental administrative act is the Ministerial Decree 560 of December $1^{\text {st }}, 2017$ - also called BIM Decree. In the decree, the Ministry of Infrastructure and Transport defines the methods and timing for the progressive adoption of specific digital methods and tools by the contracting stations, the granting authorities and economic operators. For example, the obligatory use of BIM modeling tools for construction and infrastructure in the design, construction, and management phases of the works and related checks. This decree stipulates that from 2019, all complex public works with a tender value of EUR 100 million or more must adopt a BIM approach. With a proportional logic, the same decree obliges the use of BIM for all public works from 2025 onwards, regardless of tender value.

From a normative point of view, instead, the essential reference is the ISO 19650, adopted in Italy as UNI EN ISO 10650-1 and UNIEN ISO 19650-2:2019. In the Italian case, there was a detailed regulatory status, so it was preferred to establish that the whole of UNI 11337, in all its parts, is the attachment of ISO 19650

To understand, instead, the current level of adoption of BIM in Italy, the reference document is the Rapporto Oice sulle gare BIM 2019 (OICE report on BIM tender 2019), published in February 2020 (OICE, 2020). OICE, the national association representing the Italian engineering, architecture and technicaleconomic consulting organizations, states that in 2019 BIM calls for tenders represent $8 \%$ of the market of all engineering and architecture services, with an increase of $58.3 \%$ compared to the previous year (in 2018, the increase was 263.9\% compared to 2017).

In order to go deeper into the topic of HBIM, it is useful to note, again in the same OICE report, that $63.4 \%$ of the BIM calls for tender concern renovations.

\section{BIM AND HBIM: SIMILARITIES AND DIFFERENCES}

The data and trends described in the previous paragraphs confirm the growing diffusion of BIM in Italy, but highlight that the field of application is very often the built heritage, even if with different historical and artistic characteristics. Although the data refer to the Italian situation, it is clear that all countries with a significant and widespread built heritage are in the same working condition.

In such a context, the designation of a new paradigm of BIM, firstly described by Murphy in 2009 (Murphy et al., 2009), called HBIM (Historic Build Information Modelling), becomes very relevant. The high number of scientific works in the HBIM field produced in Italy is an indication of the great interest concerning both the economic and research area.

And if we assume this new paradigm, it is necessary to define the peculiarities of both approaches: BIM and HBIM.

Much literature on HBIM (Lopez et al., 2018) (Bruno, Roncella, 2019) focuses on the differences and similarities between these two approaches. This analysis is fundamental to develop a specific training curriculum with the aim of creating new professional figures of HBIM operators.

The main difference between BIM and HBIM concerns the object of the intervention. In the first case -BIM- the aim is the design and construction of new buildings. Instead, HBIM focuses on an existing building which requires various kind of interventions: conservation, restoration, re-use, and rehabilitation.

These first, and obvious, difference determines very relevant effects, especially with respect to the knowledge of the building. In new constructions, the designer defines, independently, or through coordinated teamwork, all the characteristics of the building (shape, geometry, size, construction technologies, and materials used). We can say that the knowledge of the building, or rather "how it will be", is very precise and accurate. In the case, instead of the intervention on the built heritage, knowledge is a great challenge since it will depend on a series of analyses, more or less invasive, on the building itself. Through architectural surveys, structural investigations, tests on materials, and in-depth documentary research, it will be possible 
to collect much of the information necessary to describe the building.

An architecture, however, is not only the result of a building process. It is the outcome of a temporal process that can lead to transformations over time, and we cannot find traces of them in documents or in the building itself (especially if we do not know where to look for). The process of analysis that leads to knowledge of the building is rarely linear in nature but involves a continuous going back to the building to discover something new. While it is true that BIM systems provide the possibility of enriching the model with information at every stage of the process, it is equally true that we need a reasonable starting basis for building the model that will index all the data.

As described below, geomatics instruments and methods play a fundamental role in the knowledge of the building, but they also reveal some weaknesses that lead to essential gaps. Based on optical systems, the two most commonly used methods - laser scanner and photogrammetry- allow to know the skin of the building, but not the inside of the walls and the other hidden parts. Other destructive analyses, typical of the restoration site, such as coring on wall tests, allow a punctual knowledge, which cannot be extended, with certainty, to the whole building. Finally, analyses of a structural nature give general indications on the structure but say very little about the individual objects, which in reality constitute the essential element of BIM.

Furthermore, the diversity of subjects of intervention between BIM and HBIM - new construction or existing building - poses other problems related to the interpretation of architecture and its modeling. On the one hand, in fact, it is necessary to know the historical construction techniques in order to characterize the technological elements. A barrel vault, for example, cannot be realized only taking into account the geometric shape, but we should consider its thickness, static functioning, material, and construction technique. The same concept is described in (Adami et al., 2019) for the HBIM of the Cathedral of Mantua and especially for the modeling of the main façade, taking into account the historic constructive technology and documents.

On the other hand, it is essential to divide the complex object, the architecture, into smaller and simpler elements, the objects of BIM approach, according to a logic that is typical of information modeling. In this way, the issue of semantic classification is tackled, with all the difficulties of finding a subdivision that is functional to the intervention but respectful of the characteristics of the building and the HBIM approach (Adami et al., 2018).

Then we find the problem of modeling, that is, the passage from acquired data (usually a point cloud with direct measurement integrations or, when it is not available, a series of twodimensional drawings) to a three-dimensional parametric model. There are many researches suggesting to use tailor-made systems (Banfi, 2019) and open-source solutions (Fregonese et al., 2017). But in the labor market, this is very difficult, and so the modeling stage takes place through commercial software that has been implemented for new constructions. This choice is necessary, of course, to follow the economic, temporal, and resource optimization criteria that a real intervention requires. But it also leads to problems in the representation of some objects. And also, it forces a simplification that is not always easy. First of all, we think about the simplification of irregularities and deformations (inclined and not vertical walls, as frequent as the age of the building is high). These forces also affect the accuracy of the final geometric model. It is, therefore, necessary to take into account the difference between the accuracy of the initial data, acquired by geomatic methods, and the final data, the result of the parametric modeling phase (Adami et al., 2017).

To this is added the problem of using standard libraries for elements that are different in reality and that the restoration disciplines, even with varying degrees of intervention, struggle to make homogeneous.

Many of these issues can be, if not really solved, at least addressed through the methods of Geomatics and having clear the role of BIM and the needs of each area.

\section{ROLE OF GEOMATICS IN A HBIM TRAINING CURRICULA}

\subsection{Role of Geomatics in academic training}

Geomatics is the modern name that brings together the traditional disciplines related to measurement and control such as topography, photogrammetry, GPS, remote sensing, GIS, etc. In the training path of the architect, Geomatics plays a very different role from university to university. Very often, The courses of Architectural Survey deal with photogrammetric and laser scanner techniques, but BIM and HBIM are not addressed. Usually, these courses aim to produce, as a final result, traditional two-dimensional representations, and also threedimensional models, but they are not realized with the logic of an informative system as BIM. BIM systems are, instead, the prerogative of other disciplines, such as construction technology, and, only in a few cases, the fields of Geomatics are integrated with those of construction technology.

Engineering schools have a more in-depth approach to geomatic disciplines, both for surveying and monitoring. Also in this case, despite a greater depth, the link between Geomatics and BIM systems is not an institutional subject of the course, but, where practiced, is still a personal choice of the teacher.

We can find greater integration, instead, in post-university courses such as first and second level masters (according to the national classification) and other more specific training activities.

\subsection{Master HBIM and geomatics curriculum}

Politecnico di Milano, already active with other masters dedicated to BIM, proposes a new course dedicated to HBIM systems that starts, through geomatic methods., from a strong integration between the design and management of architecture and the documentation of architecture itself.

The aim of the master is to educate specialized operators to work on the existing heritage, through BIM systems. The course includes three main areas (conservation, plant design, and structural design) in addition to a module, preparatory to all the other three, related to the theme of the survey and digitization of buildings. As an outline of all this, some modules are linked to interoperability and data exchange through IFC, database structuring, management of safety aspects of the building site, and current regulations.

The logic of the master is to provide not only the individual skills but to relate them to each other, as already happens, without the BIM approach, in the architecture project.

The training in the geomatic field provides about 70 hours between lessons and exercises, in addition to another 50 hours, strictly related to software. We can recognize two major themes in which to divide the entire module. The first one concerns data acquisition (methods and tools for the digitization of the built environment), while the second is related to the use of collected data (use of point clouds, Scan2BIM processes, modeling types).

The first module will deal with the instruments that can be used in the process of digitizing the built environment. After providing an overview on Geomatics, data accuracy, and the statistical approach needed to evaluate methods, laser scanner 

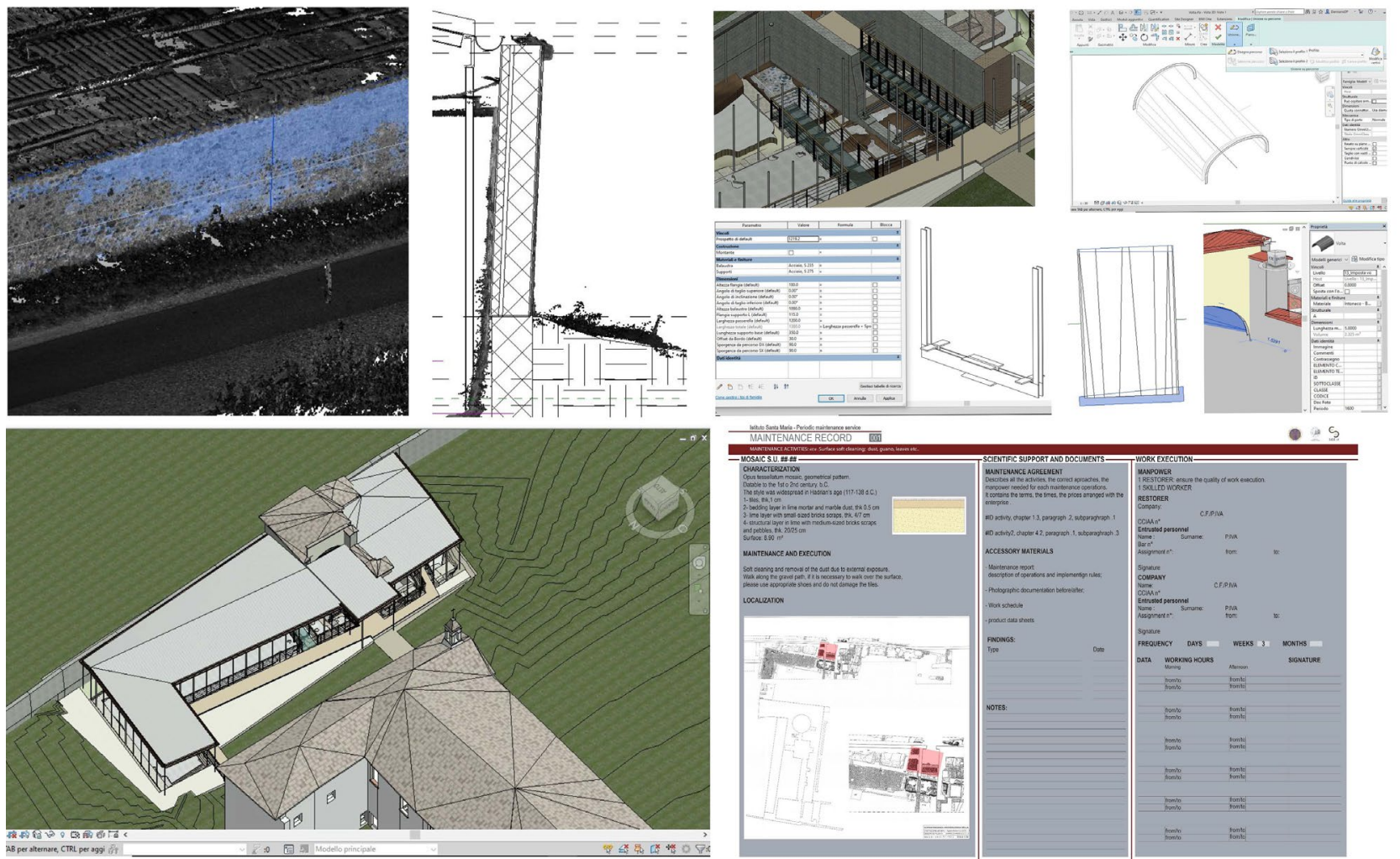

Figure 1: The design of the archaeological area next to the monastery of Santa Maria in Castiglione. The point cloud and the extraction of profiles (top, left), the modelling stage of complex element (top right), the architectural design of the new coverage (bottom, right) and the card for the planned conservation (bottom, left).

and photogrammetry, both terrestrial and from the drone, will be the main topics. Together with them, we will focus on the survey project and, more precisely, on the need to establish a reliable and durable reference system (through a topographic network), which is essential to deal with the documentation phase but also for the construction site and subsequent maintenance. The collaboration with instrument manufacturers will be essential to offer participants the latest technologies (such as SLAM-based systems). Attention will also be drawn to the relationship between precision, accuracy, object size, and BIM objectives, which is necessary to correctly design the type of documentation.

The second part of the module dedicated to Geomatics is certainly the most complex because it deals with issues that are not completely solved even in research. The Scan2BIM process will be at the center of the lessons. We will analyze different procedures and methods, more or less automatic, for the construction of the parametric BIM models. Point clouds will be the most used data in this part, and, fortunately, it will be possible to treat together both those obtained by photogrammetry and those obtained by laser scanner.

In addition, we will highlight some aspects for which there is no univocal answer yet, but which require instead to be addressed through broader and more structured reasoning. In fact, we will talk about the modeling phase and the precisions that can be reached through parametric methods. For example, thanks to the experiences brought by the co-presence of restorers, plant engineers, and structural designer, we will try to define the characteristics of each model. For example, concerning the final accuracy and the elements that cannot be missing, according to the purpose of the model. This issue recalls many aspects of the BIM world such as the classification and segmentation of data and the choice of LOD. Also on these issues, a comparison will be necessary. The federated model, a combined building information model that is compiled from several BIM models from different disciplines into one, will have to respond, starting from a single datum (the cloud of points) to the needs of conservators, plant engineers, and structural designers.

\section{LESSON LEARNED FROM A PREVIOUS EXPERIENCE}

The master designed by Politecnico di Milano for October 2020, and postponed to January 2021 for the coronavirus emergency, starts from another experience conducted in 2019. In May 2019, in fact, Politecnico di Milano organized a training course, of only 100 hours, to verify the general approach already designed for the HBIM master. We proposed a training course with a structure similar to that of the master (three main design modules in addition to Geomatics) to a small number of participants, ten recent graduates in architecture. The extracurricular internship, foreseen as a fundamental part of the course, allowed the 10 participants to develop the approach to BIM systems applied to existing heritage in architectural offices, engineering companies, and institutions for a total of 500 hours each.

The course was a good success: we received 24 applications from all over Italy, compared to the 10 open positions. But the most significant numbers concern the job placement of participants at the end of the course. Out of the eight trainees (two retired for personal or professional reasons), $75 \%$ were confirmed with other employment contracts at the societies where they did their internship, while the other $25 \%$, continue their professional career with other companies operating in the BIM field. 

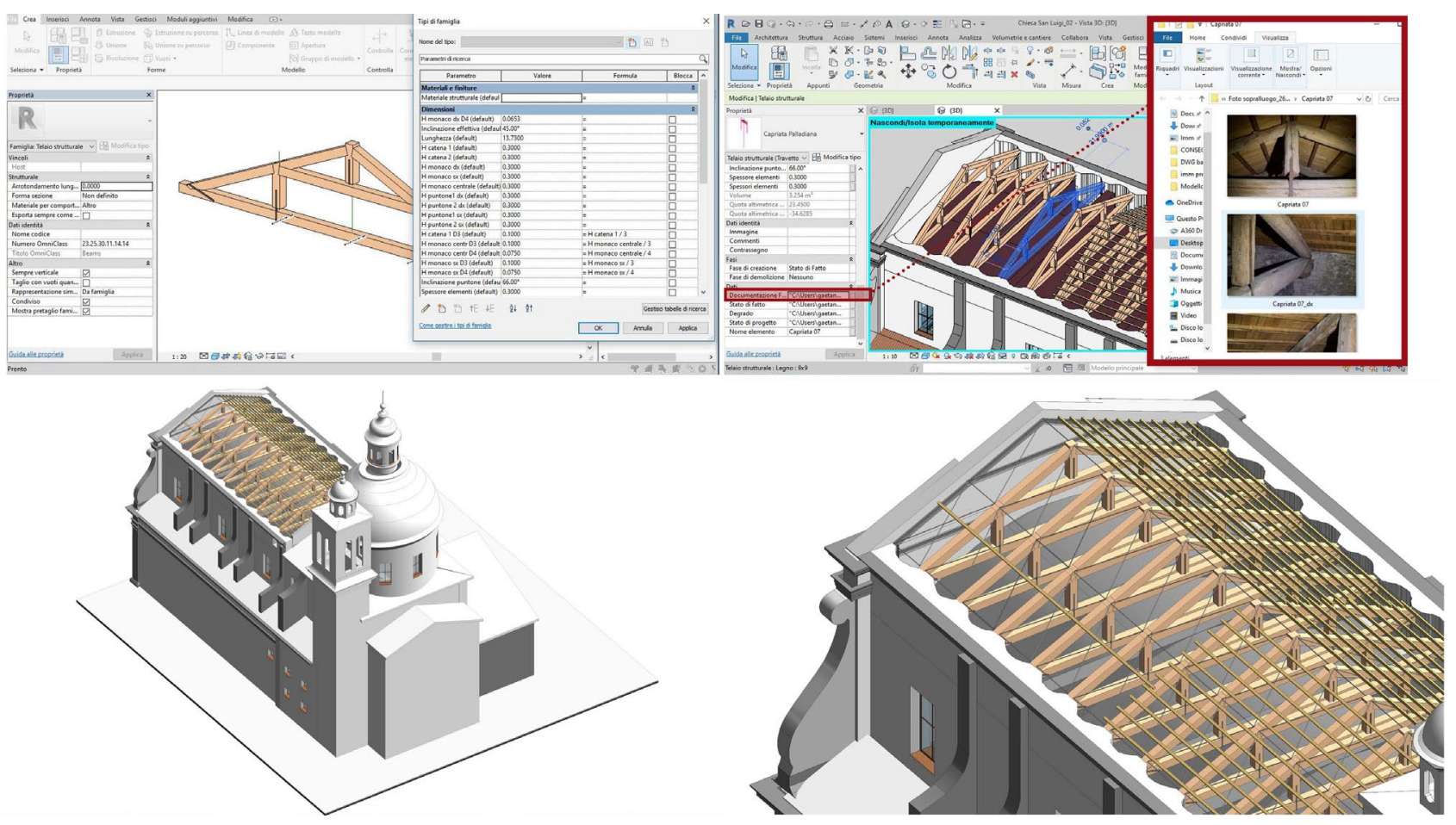

Figure 2: structural intervention on the roof of the Basilica of San Luigi in Castiglione delle Stiviere. The scheme of the single truss (top, left), the model of the roof with all the trusses and the linked photos (top, right), the entire model (bottom, left) and the detail of the structural project for the roof (bottom, right).

These numbers have convinced the Politecnico to confirm the training course in the HBIM field, but implementing it through a new master of specialization (aimed at newly graduated architects and engineers). Moreover, the same numbers have shown that the labor market is looking for people who can manage HBIM systems with particular attention to the digitization phase and to the data processing itself.

The internship experiences were carried out in engineering companies already operating in the HBIM field, but also in architectural offices and institutions owning assets that saw the need to update their operating procedures.

In the first case, the apprentices were able to take part in the BIM process, by entering a well-designed workflow: this allowed them to appropriate experience and apply methods, under the guidance of specialized personnel.

On the other hand, those who have done their internship in institutions not yet specialized, had the opportunity to think and design their BIM according to the needs of the work and the available data. Here we describe two cases of neo-architects who worked for three months in the Diocese of Mantua with the aim of designing and managing BIM in very different fields. They were housed in the office that supervises relations between the churches of the Diocese and the Superintendence (that aims to protect the heritage). So the themes concerned historical buildings and new projects connected to them.

In the first case, the newly graduated architect dealt with the data of the monastery of Santa Maria in Castiglione delle Stiviere, where the Diocese was planning a renovation project to build a hotel for pilgrims. Mainly, the assignment concerned the design, in BIM mode, of a roofing system for the preservation of the remains of a Roman villa, which are located near the monastery. The Diocese provided the BIM model of the main building and the point cloud, made with laser scanner and drone photogrammetry of the entire complex. The apprentice first studied and represented the archaeological excavations, the position of the elements important for the design (floor level, the position of the mosaics), and then designed the roof structure. He was able to manage the data related to the excavations (point cloud, superintendence reports, surveys) effectively. The last step concerned the conservation plan of the archaeological excavations, with the construction of a schedule of controls and reports all linked to the BIM model (Figure 1).

In contrast, in the Basilica of San Luigi, also in Castiglione delle Stiviere, the theme of the project was the structural consolidation of the roof. Having at her disposal the point cloud of the attic, the apprentice modeled all the trusses in BIM enviroment. To develop the model, she first studied the historical construction technologies, then defined a family of trusses corresponding to the real one and, finally, modified each instance with the real measures extracted from the point cloud. The documentation photos of the geometry and of the state of conservation were linked to the individual trusses to form a complete documentation apparatus. Even the structural interventions, designed by the structural engineer, have been included in the model as verification (Figure 2).

\section{CONCLUSIONS}

A training course for new graduates, organized by the Politecnico di Milano in 2019, helped to demonstrate the demand of the labor market for expert figures in the field of BIM applied in the field of built heritage. The training curriculum will be proposed again in an extended form as a master course starting in January 2021. Basically, the course is based on the integration of the main areas of architectural intervention (conservation, plant, and structural design) with a geomatics module that is related to all the other areas mentioned above.

In HBIM, Geomatics acquires fundamental importance because it is involved not only in the data collection (metric data) but 
also in its processing, from point cloud to the parametric model. Precisely in this passage, from BIM model to point cloud, we find all the fundamental and characteristic elements of this training path. Among them: the choice of instruments and the project of the architectural survey, the modeling methods (including segmentation), and the simplification of the model until obtaining the necessary LOD.

The training about all these topics is very important because in many cases, there are no absolute answers (even true o false), but it is necessary to put each problem in its own context. For example, it is not possible to state, in absolute terms, what the precision of the model is. Still, it will be possible to define the precision for a model made for structural or plant engineering purposes. Also, the modeling phases cannot be addressed only from a geometric point of view (for example, the shape of a barrel vault), but we should evaluate the planned interventions and the information available and required.

These examples try to demonstrate the strong correlation between Geomatics and each kind of intervention in the HBIM process. This correlation is not simply a time order of operations: first, the survey, then the project and finally, the construction site. On the contrary, it requires a continuous exchange that can only be carried out by experienced and trained personnel in the various sectors.

\section{ACKNOWLEDGMENTS}

We would like to thank all the participants of the training course for sharing opinions, requests and suggestions regarding the topics of HBIM. We would like to thank in particular the Diocese of Mantua and recent graduates Barbara Fazion and Damiano Del Posso for sharing the materials of their internship.

\section{REFERENCES}

Adami A., Scala B., Spezzoni A., 2017. Modelling and accuracy in a BIM environment for planned conservation: The apartment of Troia of Giulio Romano. Int. Arch. Photogramm. Remote Sens. Spatial Inf. Sci. 2017, XLII-2/W3, 17-23.

Adami A., Fregonese, L., Rosignoli, O., Scala, B., Taffurelli, L., and Treccani, D. 2019. Geometric survey data and historical sources interpretation for HBIM process: the case of Mantua cathedral façade, Int. Arch. Photogramm. Remote Sens. Spatial Inf. Sci., XLII-2/W11, 29-35, https://doi.org/10.5194/isprsarchives-XLII-2-W11-29-2019, 2019.

Adami A., Bruno N., Rosignoli O., Scala B., 2018. HBIM for planned conservation: A new approach to information management. In Proceedings of the Visual Heritage 2018, Vienna, Austria, 12-15 November 2018.

Banfi F. (2019). HBIM generation: extending geometric primitives and BIM modelling tools for heritage structures and complex vaulted systems. International Archives of the Photogrammetry, Remote Sensing and Spatial Information Sciences, XLII-2/W15, 139-148. https://doi.org/10.5194/isprsarchives-XLII-2-W15-139-2019.

Bruno N., Roncella R., 2019, HBIM for Conservation: A New Proposal for Information Modeling. Remote Sens. 2019, 11, 1751; doi:10.3390/rs111517514.

Fregonese, L., Taffurelli, L., Adami, A., Chiarini, S., Cremonesi, S., Helder, J., and Spezzoni, A., 2017. Survey and modelling for the BIM of Basilica of San Marco in Venice, Int. Arch. Photogramm. Remote Sens. Spatial Inf. Sci., XLII-2/W3,
303-310, https://doi.org/10.5194/isprs-archives-XLII-2-W3303-2017, 2017.

European Construction Sector Observatory, 2019. Building Information Modelling in the EU construction sector. Trend Paper Series. March 2019.

EU BIM Task group, 2018. Handbook for the introduction of Building Information Modelling by the European Public Sector, available from: http://www.eubim.eu/, last access 30/04/2020.

Lopez F.J., Lerone P.M., Llamas J., Gomez-Garcia-Bermejo J, Zalama E, 2018. A Review of Heritage Building Information Modeling (H-BIM), in Multimodal Technologies and Interact. 2018, 2, 21; doi:10.3390/mti2020021.

Murphy, M., McGovern, E., Pavia, S., 2009. Historic building information modelling (HBIM). Structural Survey 27 (4), 311 327.

OICE, 2020, Rapporto sulle gare BIM 2019 per opere pubbliche, Analisi del mercato e delle gare, Rome, 2020, from: https://www.oice.it/638197/rapporto-sulle-gare-bim-2019, last access 30/04/2020.

Panteli, C., Polycarpou, K., 1, Morsink-Georgalli, F. Z., Stasiuliene, L., Pupeikis, D., Jurelionis, A., Fokaides, A., 2020. Overview of BIM integration into the Construction Sector in European Member States and European Union Acquis. IOP Conference Series: Earth Environment Science 410 012073 .

Pavan A., Mirarchi C., Dalila C., De Gregorio M., 2020, Standard BIM, il mondo dopo la ISO 19650, from https://www.ingenio-web.it/26765-standard-bim-il-mondodopo-la-iso-19650, last access 30/04/2020. 